\title{
Extreme hot summers in China in the CMIP5 climate models
}

\author{
Guoyong Leng ${ }^{1,2} \cdot$ Qiuhong Tang $^{1} \cdot$ Shengzhi Huang $^{3}$ • \\ Xuejun Zhang ${ }^{1,4}$
}

Received: 22 April 2015 / Accepted: 29 November 2015 /Published online: 8 December 2015

(C) Springer Science+Business Media Dordrecht 2015

\begin{abstract}
Given the severe impacts of hot summers on human and natural systems, we attempt to quantify future changes in extreme hot summer frequency in China using the Coupled Model Intercomparison Project Phase 5 (CMIP5) projections. Unlike previous studies focusing on fixed future time slices, we investigate the changes as a function of global mean temperature (GMT) rise. Analyses show that extreme hot summers (June-July-August mean temperature higher than $90 \%$ quantile of 1971-2000 climatology) are projected to occur at least $80 \%$ of the time across China with a GMT rise of $2{ }^{\circ} \mathrm{C}$. The fraction of land area with extreme hot summers becoming the norm (median of future summer temperatures exceed the extreme) will increase from $\sim 15 \%$ with $0.5{ }^{\circ} \mathrm{C}$ of GMT rise to $\sim 97 \%$ with $2.5^{\circ} \mathrm{C}$ GMT rise, which is much greater than for the global land surface as a whole. A distinct spatial pattern of the GMT rise threshold over which the local extreme hot summer first becomes the norm is revealed. When averaged over the country, the GMT rise threshold is $0.96{ }^{\circ} \mathrm{C}$. Earth system models exhibit comparable results to climate system models, but with a relatively larger spread. Further analysis shows that the concurrence of hot and dry summers will increase significantly with the spatial structure of responses depending on the definition of drying. The increase of concurrent hot and dry conditions will induce potential droughts which would be more severe than those induced by only precipitation deficits.
\end{abstract}

Electronic supplementary material The online version of this article (doi:10.1007/s10584-015-1576-y) contains supplementary material, which is available to authorized users.

Qiuhong Tang

tangqh@igsnrr.ac.cn

1 Key Laboratory of Water Cycle and Related Land Surface Processes, Institute of Geographic Sciences and Natural Resources Research, Chinese Academy of Sciences, Beijing 100101, China

2 Joint Global Change Research Institute, Pacific Northwest National Laboratory, College Park, MD 20740, USA

3 State Key Laboratory Base of Eco-Hydraulic Engineering in Arid Area, Xi'an University of Technology, Xi'an 710048, China

4 University of Chinese Academy of Sciences, Beijing 100049, China 


\section{Introduction}

The occurrence of exceptional hot summers and the associated heat waves can exert severe impacts on human health, agriculture production and ecosystem productivity (Patz et al. 2005; Battisti and Naylor 2009; Lobell et al. 2012; Dong et al. 2014, 2015). During the past century, the occurrence of exceptional hot summers has been increasingly reported over the world, e.g. Europe in 2003, Moscow in 2010, Texas and Oklahoma in 2011 and eastern China in 2013 (Stott et al. 2004; Dole et al. 2011; Trenberth and Fasullo 2012; Tang et al. 2012; Sun et al. 2014; Christidis et al. 2015). According to Hansen et al. (2012). the fraction of land areas experiencing hot extreme defined as more than three standard deviations warmer than the 1951-1980 climatology has increased from $1 \%$ to about $10 \%$ for the last 30 year.

The potential changes in hot summers in response to enhanced radiative forcing have attracted increasing attentions for the past decades. Studies based on global climate models (GCMs) suggest that the frequency of extreme hot summers may increase in the twenty-first century, producing more frequent, longer and more intense heat waves (Meehl and Tebaldi 2004; Fischer and Schär 2010; Rahmstorf and Coumou 2011; Perkins et al. 2012; Coumou and Robinson 2013; Wang et al. 2015). The projected increase in extreme hot summers across GCMs raises a key question: when current hot summers will become normal in the future? Duffy and Tebaldi (2012) found that previous extremely hot summers over United States are likely to become normal by mid-century if the business-as-usual rate of greenhouse gas emissions continues. Battisti and Naylor (2009) showed that seasonal-mean temperatures are projected to exceed the most extreme values experienced during the 20th Century in many areas of the world by the end of the 21st Century. Diffenbaugh and Scherer (2011) found that an irreversible rise in summer temperatures will happen in the next 20 60 years over many parts of the tropics and the Northern Hemisphere.

It is well established that climate models exhibit different sensitivities to natural and anthropogenic climate forcing, thus resulting in discrepancy in the timing when reaching a certain level of global mean temperature (GMT) rise and the associated magnitude and patterns of regional amplification would differ significantly (Betts et al. 2011; Joshi et al. 2011; Tang and Lettenmaier 2012; Zhang et al. 2014). Projected changes in climatic extremes on fixed future time slices under different scenarios would therefore vary greatly in terms of the magnitude (Zhou et al. 2014) and the topic still remains controversial. In addition, the ongoing policy-debates among governments and organizations are more on how to limit the GMT rise to a target value to avoid dangerous impacts (Meinshausen et al. 2009; Smith et al. 2009; Randalls 2010). Indeed, understanding the regional impacts under specific global warming level can better inform policy-makers on regional mitigation and adaptation strategies. However, the possible changes in the frequency of extreme hot summers under various levels of global warming have so far not been well investigated in detail.

Based on the CMIP3 climate models, Anderson (2012) analyzed the future seasonal temperature extreme occurrences and found that the occurrence of extremes will increase significantly especially in the tropics under the $2{ }^{\circ} \mathrm{C}$ global warming. Considerable efforts have been made by Chinese scientists to investigate the climate changes in China mainly under the $2{ }^{\circ} \mathrm{C}$ global warming scenario (e.g. Jiang et al. 2009; Lang and Sui 2013; Zhang 2012; Chen and Sun 2014). Lang and Sui (2013) suggest that $2{ }^{\circ} \mathrm{C}$ global warming would lead to increase of extreme daily warm temperature events across the country. Chen and Sun (2014) confirmed that the daily warm events would be more frequent and stronger in the future and 
the situation would become worse with $3{ }^{\circ} \mathrm{C}$ global warming than the 1 and $2{ }^{\circ} \mathrm{C}$ warming scenario. Although previous studies have shown that regional extreme events increase with GMT, the social implications of the increase are rarely discussed (Dong et al. 2015). If the hot extreme events in the future become far more common than they used to be, the extreme events at present would become the new normal condition in the future. When the current extreme becomes a new norm, the society would face great challenges to adapt to the new normal condition. Therefore, the criterion can be used to reflect the regional challenge of the change in hot extremes. This study explores the probability of land areas with the extreme becoming the new norm and the GMT rise threshold over which the criterion will be crossed for different regions of China. Indeed, by determining the GMT rise level at which extreme hot summers become the norm, we can link the regional extreme challenge directly to global warming which is the most critical need for adaptation to climate change at regional scale.

Here, we focus our analysis on China where extreme hot summers have been increasingly reported and have caused far-reaching social-economic impacts (Sun et al. 2014). The research presented here expands upon previous efforts by investigating: 1) how will the occurrence of extreme hot summers respond to global warming across China? Will China experience more extreme hot summers than the global land under the same global warming amount? 2) At which level of GMT increase will the local extreme hot summer defined in the history first become the norm? 3) How will the concurrence of hot and dry summers change?

\section{Data and methodology}

The monthly mean temperature and precipitation dataset from 34 models participating in the Coupled Model Intercomparison Project Phase 5 (CMIP5) (Taylor et al. 2012) are obtained (Table S1). Compared to CMIP3 model runs, CMIP5 models incorporated substantial changes (e.g. updated model physics, higher resolutions, and new greenhouse gas emission scenarios). In addition, climate system models and earth system models (with additional biogeochemical components) are classified for the first time in the CMIP5 archive. It would definitely be valuable to compare the difference between the two subsets of climate models with respect to their projections since very limited studies have been done toward this purpose (Meehl et al. 2013). Of all the CMIP5 models used in this study, 15 are classified as earth system models and 19 as climate system models (Table S1). Since there is no universal guidance to objectively choose a suitable target grid, all the CMIP5 output are remapped to $0.5^{\circ} \times 0.5^{\circ}$ latitude-longitude spatial resolution following Zhang et al. (2014). The summer (June-JulyAugust) mean are calculated for each model. The RCP8.5 emission scenario is used in this study to highlight the largest possible changes since this scenario shows the highest level of radiative forcing up to $8.5 \mathrm{~W} \mathrm{~m}^{-2}$ with greenhouse gas concentration exceeding $1370 \mathrm{ppm}$ $\mathrm{CO}_{2}$ equivalent and cover the maximum possible GMT increase (Moss et al. 2010). Furthermore, projections based on the GMT changes as an index for climate changes are found to be independent of the emission pathways (Tang and Lettenmaier 2012; Gillett et al. 2013; Zhang et al. 2014).

The CMIP5 models have been widely evaluated from global and regional perspectives and are found to match the observations in terms of broader characteristics (Sillmann et al. 2013; Kharin et al. 2013). More detailed regional analysis over China showed that the multi-model ensemble median of CMIP5 projections are generally in good agreement with the observations in the overall patterns of changes in climatic extremes over China (Chen et al. 2013; Zhou et al. 2014; Chen and Frauenfeld 2014). Recently, Jiang et al. 
(2015) evaluated the ability of 77 GCMs participating in the Intergovernmental Panel on Climate Change (IPCC) Third (TAR), Fourth (AR4), and Fifth (AR5) Assessment Reports in reproducing the mean and interannual variability of annual and seasonal temperature and precipitation thoroughly and comprehensively. The observed gridded temperature and precipitation data used in Jiang et al. (2015) are established at $0.5^{\circ}$ horizontal resolution based on 2416 weather stations over China from the China Meteorological Administration (Wu and Gao 2013). Generally, the climate models are found to exhibit reasonable capability in capturing the spatial structure of variability of summer mean temperature and precipitation when compared to observations in China. The evaluation results by Jiang et al. (2015) which are conducted at the resolution of $0.5^{\circ}$ for the period 1961-2000 suggest that the projections of the state-of-the-art climate models are applicable for analyzing the changes in extreme hot summers in China.

An alternative approach is to bias-correct the climate projections before its use at the global scale (Warszawski et al. 2014) and regional scale (Wang and Chen 2014). In addition to the deficiency in assuming stationary of bias (Christensen et al. 2008). bias-correction techniques in adjusting the climate projection against observations would damage the inter-variable dependencies if adjusted individually (Rocheta et al. 2014) and the climate change signal (Dosio et al. 2012) although it is a common practice in impact analysis (Teutschbein and Seibert 2012). Therefore, the original climate projections obtained from the CMIP5 archive are preferred for use in this study. Nevertheless, it is still important to bear in mind that the results presented in this study should only represent the estimates of current state-of-art climate models participating in the CMIP5.

In this study, the $90 \%$ quantile of summer mean temperature in the baseline period, i.e. 1971-2000, are used as the threshold for defining the extreme hot summers. We acknowledge that the magnitude of results may differ if choosing different baseline period and/or extreme definitions. Here, the choice of $90 \%$ quantile as a threshold in this study is to a large extent arbitrary but within the range of choices by previous studies in defining seasonal extremes (Diffenbaugh and Scherer 2011; Duffy and Tebaldi 2012; Hansen et al. 2012). To address the three major goals, calculations for each model are made as follows:

1) To address the scientific question 1 , we first identify the future 30 -year periods with GMT increase by $2{ }^{\circ} \mathrm{C}$ relative to $1971-2000$ (Table S1). Specifically, the GMT for each 30-year period beginning with 1971-2000, then 1972-2001, etc. through 2100 is calculated for each simulation, and the first 30-year period in which the difference between historical 1971-2000 GMT and the mean 30-year GMT exceeded $2{ }^{\circ} \mathrm{C}$ is identified. Then, we extract the future summer mean temperature time series in the identified future periods, and count the number (frequency) of future summers with mean temperature exceeding the predefined threshold value. If the median of future summer mean temperature exceed the historical extreme, it is defined that the current extreme hot summer has become the new norm in the warming world. The fraction of land area with extreme hot summers becoming the norm at various warming levels from 0.5 to $2.5^{\circ} \mathrm{C}$ is summarized for China and global land to explore whether China will experience more risks than the global land.

2) To address the scientific question 2, we calculate the GMT rise level at which extreme hot summers first become the norm for each grid. The results based on projections by ESMs and CSMs are also examined separately to characterize the difference between the two subsets of models in CMIP5. By assuming that temperature follows the Gaussian distribution (Schär et al. 2004). changes in the mean and variability of summer mean 
temperature in the future (when extreme hot summers first become normal) relative to the baseline period are further calculated.

3) To address the scientific question 3, we count the number of future (when extreme hot summers first become normal) and historical extreme hot summers with concurrent precipitation lower than the defined thresholds based on the baseline period. To characterize the uncertainty from the definition of dry summers, three levels of dry conditions are defined, i.e. summer mean precipitation lower than the P50 (50\% quantile), P30 (30\% quantile), and P10 (10\% quantile) of historical climatology. By calculating the percentage changes in concurrent hot and dry summers, changes in the potential risks of droughts could be explored.

The calculations is first done for each model and the multi-model ensemble median which is superior to any individual model (Reichler and Kim 2008; Pierce et al. 2009) is used for analysis. The multi-model spread as measured by the standard deviation is used to characterize the associated structural uncertainty. It should be noted that our definition of global warming is relative to 1971-2000 rather than the preindustrial era as agreed upon by the international community (UNFCCC 2009). Readers can simply subtract our estimates by $0.8{ }^{\circ} \mathrm{C}$ to get the information relative to pre-industrial era, given the fact that the end of the 20th Century are approximately $0.8^{\circ} \mathrm{C}$ warmer than the pre-industrial era (IPCC 2007).

\section{Results}

\subsection{Changes in extreme hot summers frequency with global warming}

Figure 1a show the multi-model ensemble median frequency of extreme hot summers when GMT increase by $2{ }^{\circ} \mathrm{C}$ relative to $1971-2000$. The frequency of extreme hot summers exhibits an evident geographical gradient where the largest magnitudes of frequency occur in central and southern China followed by western and northeastern China. In South China, extreme summers are projected to occur at least $90 \%$ of time. Results based upon RCP4.5 scenario (see Figure S1) are found to be very similar to those from the RCP8.5 scenario, suggesting that our results as a function of GMT are semblable across emission scenarios. Notably, the frequency of extreme hot summers will be higher than $50 \%$ over the whole country. In other words, given a future $2{ }^{\circ} \mathrm{C}$ GMT rise, current summer temperature extremes will effectively become the norm across the whole country.

Figure $1 \mathrm{~b}$ shows the changes of land fractions (\%) with extreme hot summers becoming the norm under GMT rise levels from 0.5 to $2.5{ }^{\circ} \mathrm{C}$ for China and global land. From Fig. $1 \mathrm{~b}$ we find that given a GMT increase of $0.5^{\circ} \mathrm{C}$ relative to the $1971-2000$, on average $15 \%$ of the land surface grids over China will have extreme hot summers becoming the norm. This areal extent increases rapidly with increasing GMT, on average reaching $70 \%$ for a GMT increase of $1{ }^{\circ} \mathrm{C}$ and $97 \%$ for a GMT increase of $2{ }^{\circ} \mathrm{C}$. Moreover, the agreements among models tend to increase with global warming amounts, suggesting a robust increase of extreme hot summer occurrences with climate warming. Notably, the land fraction with extreme hot summers becoming the norm is much larger in China than the global land as a whole. This suggest that more frequent extreme hot summers will occur in China than the global land even under the same level of green-house gas forcing and subsequent GMT rise. For example, with $1{ }^{\circ} \mathrm{C}$ GMT rise, over $70 \%$ of the areas across China will routinely experience current extreme hot summers whereas this number is $52 \%$ for the global land area. 

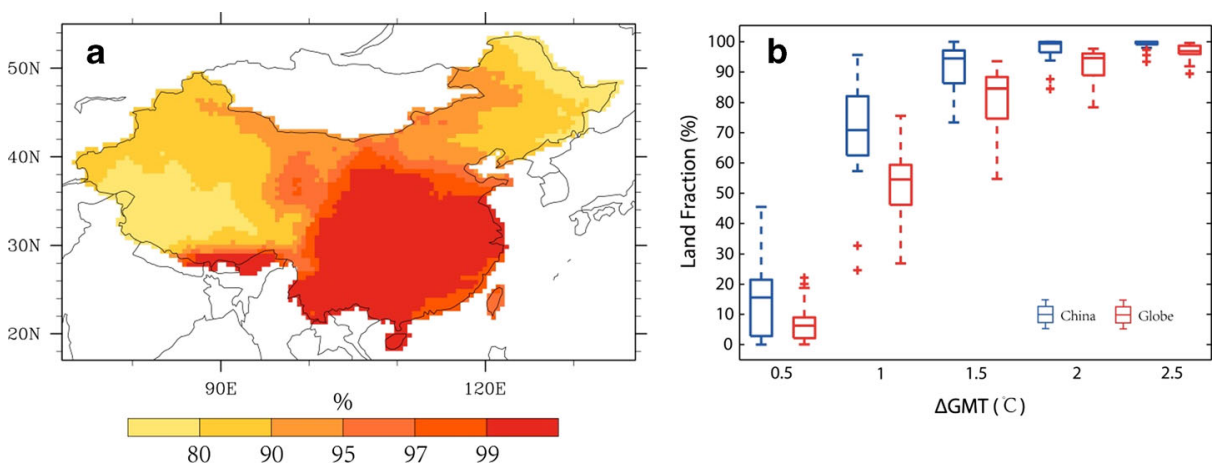

Fig. 1 a Multi-model ensemble median frequency (\%) of extreme hot summers (summer mean temperature higher than the $90 \%$ quantile of historical climatology in 1971-2000) under $2{ }^{\circ} \mathrm{C}$ global warming. b Fraction (\%) of China' and global land area where extreme hot summers become normal with global mean temperature increase from 0.5 to $3{ }^{\circ} \mathrm{C}$

\subsection{At which level of GMT rise will local extreme hot summers first become the norm?}

The non-linear changes of land fractions with extreme hot summers becoming the norm in response to increasing GMT rise (Fig. 1b) further imply that extreme hot summers would become the norm even before $2{ }^{\circ} \mathrm{C}$ global warming in specific regions. Hence, a key question arises as to at which level of GMT rise the extreme hot summer will become the norm for the grid-points? Fig. 2a shows the multi-model ensemble median of GMT rise, relative to the baseline period, at which the given grid-point's median summer temperature in 30 year period first surpass the grid-point's defined extreme value. The spatial structure of GMT rise levels at which the extreme hot summers first become the norm revealed a distinct regional discrepancy. Specifically, $0.8^{\circ} \mathrm{C}$ global warming is enough to make the extreme hot summers becoming the
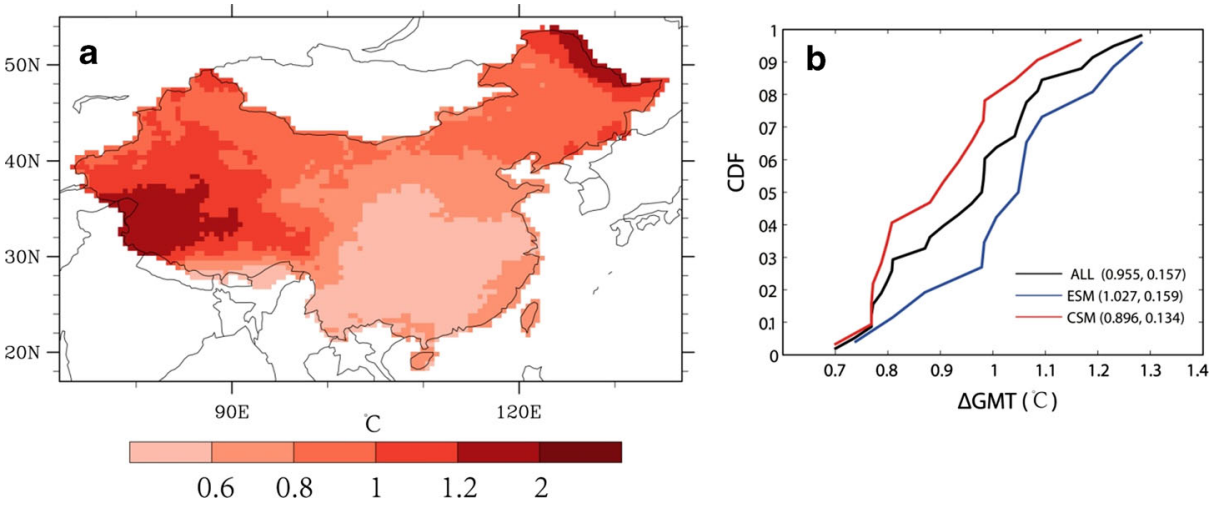

Fig. 2 a Multi-model ensemble median of the global mean temperature (GMT) rise threshold $\left({ }^{\circ} \mathrm{C}\right)$ at which local extreme hot summers first becomes the norm at the grid scale. b Cumulative distribution function of country mean GMT rise threshold $\left({ }^{\circ} \mathrm{C}\right)$ by all the CMIP5 climate models (ALL, black line), earth system models (ESM, blue line) and climate system models (CSM, red line). The corresponding median and standard deviation among the models are shown in the bracket. Note: we first calculate the GMT rise threshold for each grid, and then the mean value over the country is obtained for each model. Based on the estimates by different models, the cumulative distribution function is constructed to characterize the inter-model range 
norm in much of the south, east and central China. In the northwestern and northeastern China, such a situation could arise given a future $1{ }^{\circ} \mathrm{C} \sim 1.2{ }^{\circ} \mathrm{C}$ increase in GMT. As shown should GMT increase by $\sim 2{ }^{\circ} \mathrm{C}$, extreme hot summers will become the norm in small portion of Tibetan Plateau and Northeast China.

When averaged over the country, the threshold for resulting in extreme hot summer first becoming the norm is $0.96{ }^{\circ} \mathrm{C}$ of GMT rise as projected by the CMIP5 climate model median. We note that the range between the individual models is high (Fig. 2b). Indeed, for certain models the average GMT rise threshold can be as high as $1.3^{\circ} \mathrm{C}$ while the lowest is $0.7^{\circ} \mathrm{C}$. In addition, it is found that earth system models exhibit comparable results with climate system models. But the spread by earth system models $\left(0.159^{\circ} \mathrm{C}\right)$ is relatively larger than that by climate system models $\left(0.134{ }^{\circ} \mathrm{C}\right)$. This suggests that compared to climate system models, earth system models may not necessarily narrow down the uncertainties in projections of extreme hot summer frequency, although additional biogeochemical components of various complexity are incorporated.

Figure 3 shows the multi-model ensemble median of changes in the mean $\left({ }^{\circ} \mathrm{C}\right)$ and variability $\left({ }^{\circ} \mathrm{C}\right)$ of future summer mean temperature (when extreme hot summer first becomes the norm), relative to the baseline period. By comparing the magnitude of changes between the two statistic features, we can get a general insight on factors contributing to the significant rise of extreme hot summers at the grid scale. Increase in the mean by more than 0.3 are found over the country, with the largest increase (larger than 1) over much of northeastern and northwestern part of China (Fig. 3a). In addition, the changes are much larger than the inter-model spread (Fig. 3b). In contrast, the changes in variability lower than 0.1 are projected over much of the country and comparable magnitude of inter-model spread is found. Taken together, the
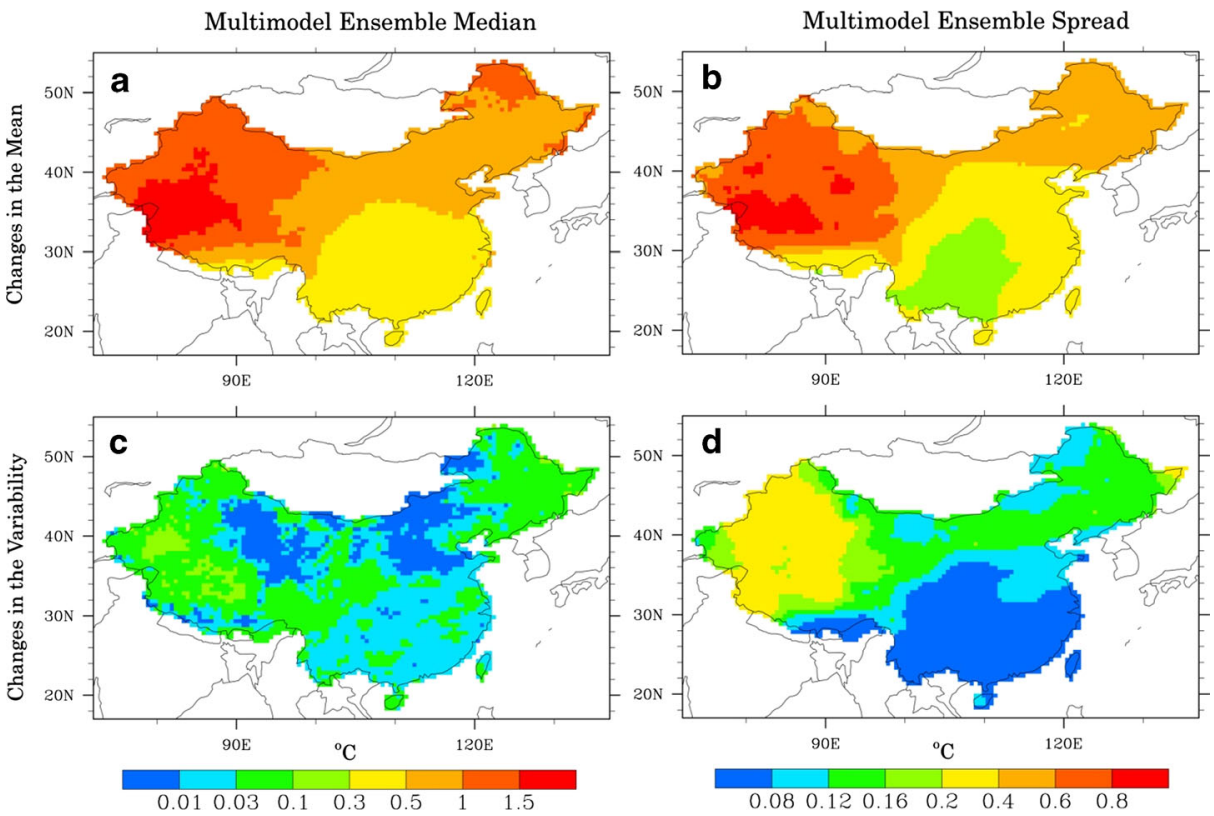

Fig. 3 Multi-model ensemble median of changes $\left({ }^{\circ} \mathrm{C}\right)$ in the (a) mean and (c) variability of summer mean temperature. The corresponding inter-model spread is shown in (b) and (d). Note: The historical period is 19712000 while the future periods are those when local extreme hot summers first become the norm (see Fig. 2a) 
changes in the variability are several times lower than that of mean across the country. This implies the situation that extreme hot summers become the norm could be statistically explained by the shift of mean of distribution rather than the variability (Schär et al. 2004; Katz et al. 1992).

\subsection{Changes in concurrence of hot and dry summers}

Global warming will induce changes not only in the extreme temperature but also the extreme precipitation (Tebaldi et al. 2006; Sillmann et al. 2013b). Here, if the temperature in a given summer is higher than the 90th percentile of historical climatology and its precipitation is lower than the predefined threshold, it is defined as the hot and dry summer. Figure 4 shows the percentage changes (\%) in the number of concurrence of hot and dry summers with summer mean precipitation lower the $50 \%$ quantile (P50), $30 \%$ quantile (P30), and $10 \%$
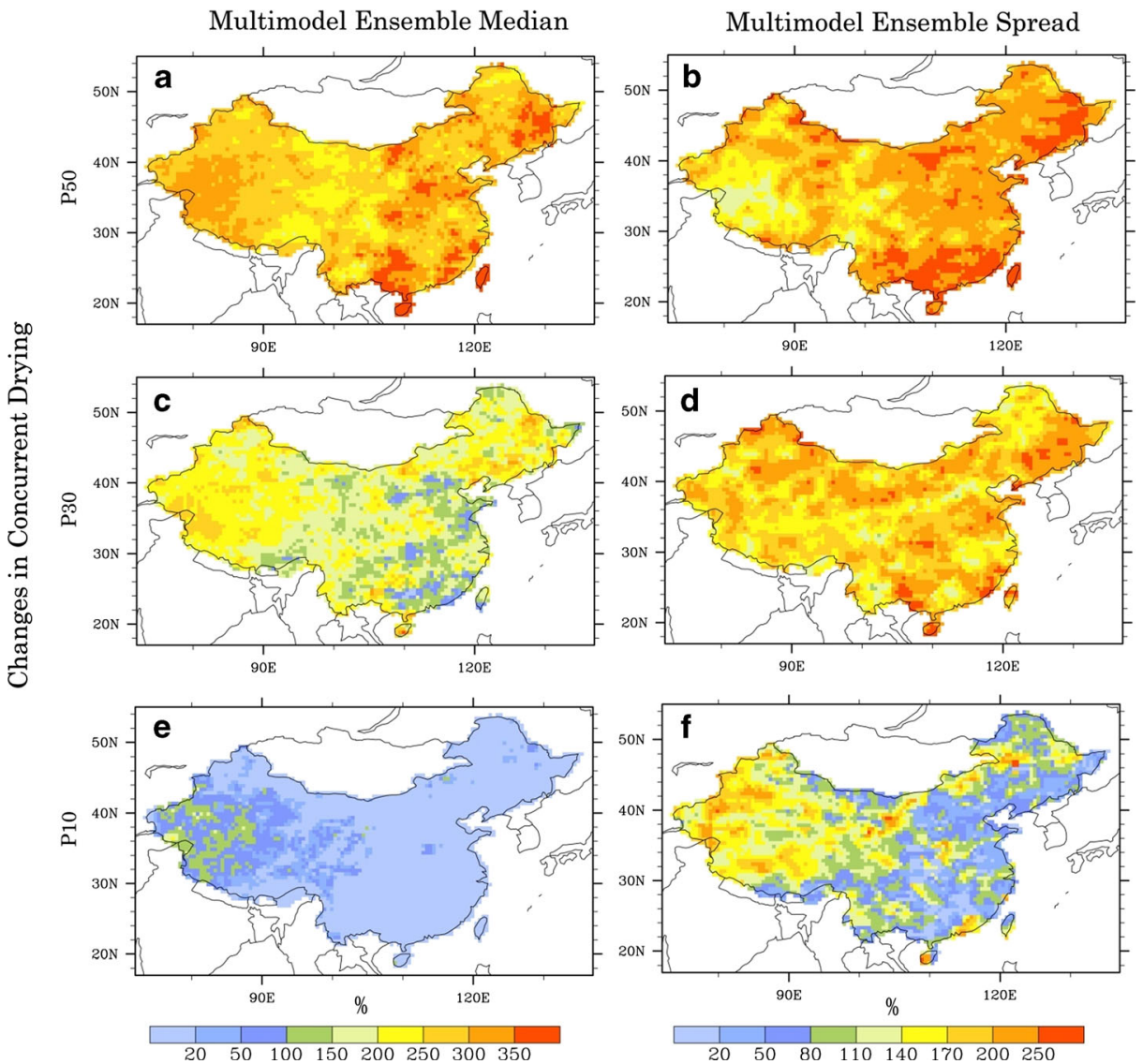

Fig. 4 Multi-model ensemble median of percentage changes (\%) in the number of concurrent hot and dry summers with summer mean precipitation lower the (a) $50 \%$ quantile, (c) $30 \%$ quantile and (e) $10 \%$ quantile of historical climatology. The corresponding inter-model spread is shown in (b), (d) and (f). Note: if the temperature in a given summer is higher than the 90th percentile of historical climatology and its precipitation is lower than the predefined threshold, it is defined as the hot and dry summer. The historical period is 1971-2000 while the future periods are those when local extreme hot summers first become the norm (see Fig. 2a) 
(P10) of historical climatology respectively. As shown in Fig. 4a, the concurrence of hot and P50 dry summers will increase by more than $200 \%$ across the country ( $99.47 \%$ of land areas) and the changes is much larger than the inter-model spread (Fig. 4b). For the percentage changes in occurrences of hot summers with P30 and P10 drying, the magnitudes become much lower. Specifically, only $43.45 \%$ and $0.07 \%$ of land areas will experience increases greater than $200 \%$ in the frequency of hot and P30 and P10 drying respectively (Table S2).

Our results suggest that the projected increase of concurrent high temperature and low precipitation will lead to potential increase of droughts over much of the country in the future. What's more, compared to those induced by only precipitation deficits, these potential droughts if occurred will be more severe and pronounced as demonstrated in the 2003 European drought (Fink et al. 2004). 2010 Russian drought (Trenberthand Fasullo 2012) and the current California droughts (AghaKouchak et al. 2014). In addition, it is found that the largest percentage increase of concurrent hot and P50 dry summers are expected in parts of northern, central and southern China whereas the largest percentage increase of concurrent hot and P30 and P10 drying are found over arid and semi-arid regions of western China. This suggests that the spatial structures of response of concurrent hot and dry summers are indeed depending on the drying definitions. And the arid regions in western China are especially prone to the extreme (P30 and P10) drying than moderate (P50) drying in future hot summers compared to other regions across China.

\section{Conclusions}

Global warming has led to increased frequency of heat extremes on monthly to seasonal time scales, causing a broad array of severe impacts on natural and human systems. Most of previous studies on extreme hot summers focus their analysis on specific future time periods and the projected changes in climatic extremes on fixed future time slices vary greatly in terms of the magnitude under different emission scenarios (Zhou et al. 2014). This paper explored the changes in extreme hot summers as a function of GMT rise based on the CMIP5 climate projections. Specifically, this study explores the probability of land areas with extreme hot summer becoming the new norm and the GMT rise threshold over which the criterion will be crossed for different regions of China.

Here, the 90th percentile value of the historical climatology of 1971-2000 is used as the threshold for the extreme hot summer for each grid. It should be noted that quantitative values of the results may vary if employing different definitions of extremes (Perkins et al. 2012). We find that given a $2{ }^{\circ} \mathrm{C}$ increase in GMT, relative to the $1971-2000,97 \%$ of the land surface in China will experience summer mean temperatures that exceed the historical extreme value at least $50 \%$ of the time. In other words, historical hot summers will become the norm for $97 \%$ of the land surface. Compared with the response across the global land, a given GMT increase would result in more fractions of China's land surface with extreme hot summers becoming the norm.

Further, we find that extreme hot summers will become the norm for a large portion of the land-surface even before GMT increase by $2{ }^{\circ} \mathrm{C}$. Specifically, in south China, a future $0.8{ }^{\circ} \mathrm{C}$ GMT increase is enough to result in summers with median temperature value exceeding the historical extreme value. While $1 \sim 1.2^{\circ} \mathrm{C}$ global warming is sufficient to make this situation happen across almost the whole country. Only a portion of west Tibetan platen and northeastern China requires GMT increase by more than $2{ }^{\circ} \mathrm{C}$ to result in these situations. Averaged over the country, the multi-model ensemble median of GMT rise threshold is $0.96{ }^{\circ} \mathrm{C}$, with the 
inter-model variation up to $0.16{ }^{\circ} \mathrm{C}$. In addition, earth system models exhibited comparable results with climate system models, but with a relatively larger spread. Statistically, the significant increase of extreme hot summers are mainly due to the shifting mean of distribution rather than the variability although more efforts are needed to quantitatively isolate the extreme changes from changes of various distribution components (e.g. mean, variance and skewness/ higher order moments). This finding can also explain the larger fraction of land areas with extreme hot summer becoming the norm over China than the global land (Fig. 1b) given the fact that China warms faster than the global average (Lang and Sui 2013; Chen and Sun 2014).

This study stands out from previous regional and global scale efforts (e.g. Battisti and Naylor 2009; Diffenbaugh and Scherer 2011; Anderson 2012; Duffy and Tebaldi 2012) by further analyzing the concurrent drying accompanying extreme hot summers and the projected changes. Our result show that concurrence of hot and dry summers will increase significantly in the future and the spatial structure of responses are depending on definitions of drying. The arid and semi-arid western China are especially prone to the percentage increase of extreme drying (precipitation lower than the historical $30 \%$ or $10 \%$ quantile) in the future hot summers than moderate (precipitation lower than the historical $50 \%$ quantile) drying compared to other regions.

Although we cannot yet expect models to accurately reproduce observed absolute quantities or rates of change in extreme climate (Tebaldi et al. 2006; Sillmann et al. 2013a). it is still important to bear in mind the bias, especially in modeled variability when interpreting the findings of this study. Specifically, models underestimating temperature variability tend to show a larger exceedance rates and vice versa (Sillmann et al. 2014). Overall, overestimation in term of the magnitude of variability is found for most GCMs across the country, but underestimation is found over part of southeast China for temperature variability and south China for precipitation variability (Jiang et al. 2015). Hence, caution should be taken in interpreting the findings in the areas where bias exists against observations as found by Jiang et al. (2015)

It is not possible to quantitatively attribute the changes to complex interactions between the processes represented in models by analyzing the model outputs alone. Summer temperature extremes in southeast China are found to be associated with the westerly jet in the midlatitudes and circumglobal teleconnection (Wang et al. 2013) and the El Niño-Southern Oscillation (ENSO) and atmospheric circulations in the East Asian summer monsoon (Wang et al. 2014). Studies also suggest that the anthropogenic emission of greenhouse gases is the major driver of the increasing frequency of hot summers in eastern China, with rapid urbanization contributing as the secondary factor (Sun et al. 2014). While we do not attempt to perform a rigorous attribution study, we seek to examine a large suite of climate simulations from multiple models to identify common features of projected extreme hot summers in the future. Our results suggest that with global warming, the occurrences of extreme hot summers are projected to increase greatly and the same forcing would cause more risks of extreme hot summers in China than the global land. Importantly, distinct spatial patterns do exist in the global warming threshold for resulting in local extreme hot summer first becoming the norm, emphasizing the need for regional specific adaptation and mitigation strategies. We highlight that the projected increase of concurrent hot and dry summers will induce more potential droughts which would be more severe than those induced by only precipitation deficits. The findings based on the CMIP5 models can better inform efforts to reduce the vulnerability associated with extreme hot summers across China if the world's greenhouse gas emissions continue. 
Acknowledgments We thank the editor and four anonymous reviewers for their thoughtful suggestions and comments that led to substantial improvements of the manuscript. This work was supported by the National Basic Research Program of China (Grant No. 2012CB955403), National Natural Science Foundation of China (Grant Nos. 41425002 and 41171031). We acknowledge the World Climate Research Programme's Working Group on Coupled Modelling, which is responsible for CMIP, and we thank the climate modelling groups for producing and making available their model output. For CMIP the U.S. Department of Energy's Program for Climate Model Diagnosis and Intercomparison provides coordinating support and led development of software infrastructure in partnership with the Global Organization for Earth System Science Portals.

\section{References}

AghaKouchak AL, Mazdiyasni CO, Farahmand A (2014) Global warming and changes in risk of concurrent climate extremes: insights from the 2014 California drought. Geophys Res Lett 41:8847-8852

Anderson BT (2012) Intensification of seasonal extremes given a $2{ }^{\circ} \mathrm{C}$ global warming target. Clim Chang 112 : 325-337

Battisti DS, Naylor RL (2009) Historical warnings of future food insecurity with unprecedented seasonal heat. Science 323(5911):240-244

Betts RA et al (2011) When could global warming reach $4{ }^{\circ} \mathrm{C}$ ? Phil. Trans R Soc A 369:67-84

Chen H (2013) Projected change in extreme rainfall events in China by the end of the 21st century using CMIP5 models. Chin Sci Bull 58:1462-1472

Chen L, Frauenfeld OW (2014) Surface air temperature changes over the twentieth and twenty-first centuries in China simulated by 20 CMIP5 models. J Clim 27:3920-3937

Chen H, Sun J (2014) Changes in climate extreme events in China associated with warming. Int J Climatol. doi: $10.1002 /$ joc. 4168

Christensen JH, Boberg F, Christensen OB, Lucas-Picher P (2008) On the need for bias correction of regional climate change projections of temperature and precipitation. Geophys Res Lett 35, L20709

Christidis N, Jones GS, Stott PA (2015) Dramatically increasing chance of extremely hot summers since the 2003 European heatwave. Nat Clim Chang 5:46-50

Coumou D, Robinson A (2013) Historic and future increase in the global land area affected by monthly heat extremes. Environ Res Lett 8:034018

Diffenbaugh NS, Scherer M (2011) Observational and model evidence of global emergence of permanent, unprecedented heat in the 20th and 21st centuries. Clim Chang 107:615-624

Dole R, Hoerling M, Perlwitz J, Eischeid J, Pegion P, Zhang T, Quan X, Xu T, Murray D (2011) Was there a basis for anticipating the 2010 Russian heat wave. Geophys Res Lett 38, L06702

Dong W, Liu Z, Zhang L, Tang Q, Liao H, Li X (2014) Assessing heat health risk for sustainability in Beijing's urban heat island. Sustainability 6(10):7334-7357

Dong W, Liu Z, Liao H, Tang Q, Li X (2015) New climate and socio-economic scenarios for assessing global human health challenges due to heat risk. Clim Chang. doi:10.1007/s10584-015-1372-8

Dosio A, Paruolo P, Rojas R (2012) Bias correction of the ENSEMBLES high resolution climate change projections for use by impact models: analysis of the climate change signal. J Geophys Res 117, D17110

Duffy PB, Tebaldi C (2012) Increasing prevalence of extreme summer temperatures in the U.S. Clim Chang 111(2):487-495

Fink AH, Br"ucher T, Kr"uger A, Leckebusch GC, Pinto JG, Ulbrich U (2004) The 2003 European summer heatwaves and drought—synoptic diagnosis and impacts. Weather 59:209-16

Fischer EM, Schar C (2010) Consistent geographical patterns of change in high impact European heat waves. Nat Clim Chang 3:398-403

Gillett NP, Arora VK, Matthews D, Allen MR (2013) Constraining the ratio of global warming to cumulative CO2 emissions using CMIP5 simulations. J Clim 26:6844-6858

Hansen J, Sato M, Ruedy R (2012) Perception of climate change. Proc Natl Acad Sci U S A 109(37):E2415-E2423

Jiang D, Zhang Y, Sun J (2009) Ensemble projection of 1-3 ${ }^{\circ} \mathrm{C}$ warming in China. Chin Sci Bull 54:3326-3334

Jiang D, Tian Z, Lang X (2015) Reliability of climate models for China through the IPCC Third to Fifth Assessment Reports. Int J Climatol. doi:10.1002/joc.4406

Joshi $\mathrm{M}$ et al (2011) Projections of when temperature change will exceed $2{ }^{\circ} \mathrm{C}$ above pre-industrial levels. Nat Clim Chang 1:407-412

Kharin VV, Zwiers FW, Zhang X, Wehner M (2013) Changes in temperature and precipitation extremes in the CMIP5 ensemble. Clim Chang 119(2):345-357 
Lang X, Sui Y (2013) Changes in mean and extreme climates over China with a $2{ }^{\circ} \mathrm{C}$ global warming. Chin Sci Bull 58:1453-1461

Lobell DB, Sibley A, Ivan Ortiz-Monasterio J (2012) Extreme heat effects on wheat senescence in India. Nat Clim Chang 2:186-189

Meehl GA, Tebaldi C (2004) More intense, more frequent, and longer lasting heat waves in the 21st century. Science 305:994-997

Meehl GA, Washington WM, Arblaster JM, Hu A, Teng H, Kay JE, Gettelman A, Lawrence DM, Sanderson BM, Strand WG (2013) Climate change projections in CESM1 (CAM5) compared to CCSM4. J Clim 26: 6287-6308

Meinshausen $\mathrm{M}$ et al (2009) Greenhouse-gas emission targets for limiting global warming to $2{ }^{\circ} \mathrm{C}$. Nature 458 : 1158-1162

Moss RH et al (2010) The next generation of scenarios for climate change research and assessment. Nature 463: $747-756$

Patz JA, Campbell-Lendrum D, Holloway T, Foley JA (2005) Impact of regional climate change on human health. Nature 438:310-317

Perkins SE, Alexander LV, Nairn JR (2012) Increasing frequency, intensity and duration of observed global heatwaves and warm spells. Geophys Res Lett 39, L20714

Pierce DW, Barnett TP, Santer BD, Gleckler PJ (2009) Selecting global climate models for regional climate change studies. Proc Natl Acad Sci U S A 106:8441-8446

Rahmstorf S, Coumou D (2011) Increase of extreme events in a warming world. Proc Natl Acad Sci U S A 108(44):17905-17909

Randalls S (2010) History of the $2{ }^{\circ} \mathrm{C}$ climate target. Wiley Interdiscip Rev: Clim Chang 1:598-605

Reichler T, Kim J (2008) How well do coupled models simulate today’s climate? Bull Am Meteorol Soc 89:303-311

Rocheta E, Evans JP, Sharma A (2014) Assessing atmospheric bias correction for dynamical consistency using potential vorticity. Environ Res Lett 9(12):124010

Schär C et al (2004) The role of increasing temperature variability in European summer heatwaves. Nature 427: $332-336$

Sillmann J, Kharin VV, Zhang X, Zwiers FW, Bronaugh D (2013) Climate extremes indices in the CMIP5 multimodel ensemble: part 1. Model evaluation in the present climate. J Geophys Res 118:1716-1733

Sillmann J, Kharin VV, Zwiers FW, Zhang X, Bronaugh D, Donat MG (2014) Evaluating modelsimulated variability in temperature extremes using modified percentile indices. Int J Climatol 34: 3304-3311

Smith JB et al (2009) Assessing dangerous climate change though an update on the International Panel on Climate Change (IPCC) "reasons for concern". Proc Natl Acad Sci U S A 106:4133-4137

Stott P, Sone DA, Allen MR (2004) Human contribution to the European heatwave of 2003. Nature 432:610-613

Sun Y, Zhang X, Zwiers FW, Song L, Wan H, Hu T, Yin H, Ren G (2014) Rapid increase in the risk of extreme summer heat in Eastern China. Nat Clim Chang 4:1082-1085

Tang Q, Lettenmaier DP (2012) 21st century runoff sensitivities of major global river basins. Geophys Res Lett 39, L06403

Tang Q, Leng G, Groisman PY (2012) European hot summers associated with a reduction of cloudiness. J Clim 25:3637-3644

Taylor KE, Stouffer R, Meehl GA (2012) An overview of CMIP5 and the experiment design. Bull Am Meteorol Soc 93:485-498

Tebaldi C, Hayhoe K, Arblaster JM, Meehl GA (2006) Going to the extremes. Clim Chang 79:185-211

Teutschbein C, Seibert J (2012) Bias correction of regional climate model simulations for hydrological climatechange impact studies: review and evaluation of different methods. J Hydrol 456:12-29

Trenberth KE, Fasullo JT (2012) Climate extremes and climate change: the Russian heat wave and other climate extremes of 2010. J Geophys Res 117, D17103

Wang L, Chen W (2014) A CMIP5 multimodel projection of future temperature, precipitation, and climatological drought in China. Int J Climatol 34:2059-2078

Wang W, Zhou W, Wang X, Fong S, Leong KC (2013) Summer high temperature extremes in Southeast China associated with the East Asian jet stream and circumglobal teleconnection. J Geophys Res Atmos 118:83068319

Wang W, Zhou W, Chen D (2014) Summer high temperature extremes in Southeast China: bonding with the El Niño-Southern oscillation and East Asian summer monsoon coupled system. J Clim 27:4122-4138

Wang W, Zhou W, Li Y, Wang X, Wang D (2015) Statistical modeling and CMIP5 simulations of hot spell changes in China. Clim Dyn 44:2859-2872

Warszawski L, Frieler K, Huber V, Piontek F, Serdeczny O, Schewe J (2014) The Inter-Sectoral Impact Model Intercomparison Project (ISI-MIP): project framework. Proc Natl Acad Sci U S A 111:3228-3232 
Wu J, Gao XJ (2013) A gridded daily observation dataset over China region and comparison with the other datasets. Chin J Geophys 56:1102-1111

Zhang Y (2012) Projections of $2.0^{\circ} \mathrm{C}$ warming over the globe and China under RCP4.5, Atmos. Ocean Sci Lett 5:514-520

Zhang X, Tang Q, Zhang X, Lettenmaier DP (2014) Runoff sensitivity to global mean temperature change in the CMIP5 models. Geophys Res Lett 41:5492-5498

Zhou B, Qiuzi Han Wen XY, Song L, Zhang X (2014) Projected changes in temperature and precipitation extremes in China by the CMIP5 multimodel ensembles. J Clim 27:6591-6611 